\title{
Ética da argumentação retórica antiga / retórica moderna
}

\author{
JOÃO PEDRO MENDES \\ Departamento de Filosofia \\ Universidade de Brasília
}

RESUMO: A arte da controvérsia - dialética - lida com o verdadeiro e seu discernimento do falso; a arte da argumentação - retórica - opera no terreno do plausível, do verossímil, para mover opções $e$ influenciar preferências. A natureza humana é plasmada do afetivo e do racional, cabendo à filosofia/dialética a esfera do segundo, e à retórica a.do primeiro. Enquanto a dialética age sobre a mente do interlocutor, a retórica age sobre a vontade, as emoções e as paixões, para captar sua adesão. Na medida em que a vivência prática nem sempre se coaduna com as luzes da razão, ao gerar-se a persuasão e inexistindo uma lógica dos juízos de valor, a conduta do homem cai sob o domínio da ética, suscitando um mundo de questões, da manipulação à sedução, do capricho à influência da passionalidade, da cegueira e auto-ilusão à usurpação da liberdade individual. Por outras palavras, a filosofia busca verdades impessoais; a retórica procura fazer prevalecer uma opinião sobre outra, de pessoa a pessoa. É daqui que se levantam as questōes éticas. PALAVRAS-CHAVE: Ética, retórica, teoria da argumentação, filosofia.

A retórica - arte de argumentar para convencer - situa-se na fronteira que separa o verdadeiro do falso, contrapondo-se à sua arquiinimiga, a dialética, cujo horizonte é tão-somente a verdade.

Para delimitarmos seu domínio, imprescindível se torna definir Verdade, tarefa maior de toda a filosofia, sempre tentada e jamais cumprida. Como técnica, a Retórica lança mão de recursos, expedientes e artifícios próprios, para atingir seus fins. Atua, por isso, numa zona teoricamente neutral, valendo-se de armas específicas, não para separar dois contendores inconciliáveis, mas para rendê-los um ao outro, de acordo com sua estratégia de induzir para triunfar. A Ética opera com juízos valorativos sobre a conduta humana, no horizonte do bem e do mal. A arte do retor é o domínio da linguagem para influenciar a mente do ouvinte, nela incutindo o seu desígnio; a do eticista é perscrutar ânimos, e apreciar comportamentos. Os limites de ambos são os apontados por Schopenhauer na transposição logicamente inadmissível, mas eticamente sustentável, do plano gnosioló- 
gico para o ontológico: "O estudo da ciência do Belo ainda não produziu um só artista, talqualmente o estudo da moral um único homem honesto" (Schopenhauer, 1844 , p. 72).

O nosso problema ao debatermos as relações entre ética e argumentação é este: terá o homem o direito de utilizar tais armas?

Mas será possível definir verdade discernindo-a de tudo o que ela não é? Antes de mais, atentemos na estrutura etimológica do termo "definir". Como é sabido, a linguagem primária do homem origina-se do concreto. Foi longo o caminho para que ela traduzisse conceitos, abstraçōes. Sem irmos longe demais, o termo latino para denotar o marco divisório ou limitativo de qualquer porção de terra era exatamente finis. O prefixo de indica movimento de cima para baixo. Por conseguinte, definir é cravar ou fincar um objeto demarcatório - pedra, pau, osso, etc. - que delimite um espaço, determine uma fronteira, assinale raias, fixe balizas. Definição é, portanto, o ato ou efeito de separar o que uma coisa é daquilo que

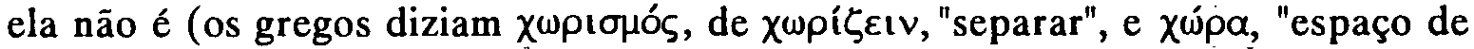
terra limitado e ocupado por alguém ou por alguma coisa"). Ora, como íamos

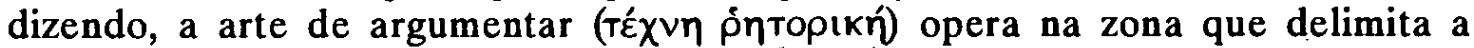
verdade da falsidade, ou seja, o seu terreno é o da verossimilhança, da parecença, da plausibilidade, da possibilidade de ser ou não ser. Enquanto arte ou utilização pelo homem do poder de dominar a matéria lingüística para comunicar-se, coube aos gregos traçar-lhe os lineamentos. A Retórica é uma invenção dos helenos. Para eles, o que verdadeiramente distingue o homem do bruto é a posse do lógos. Com este vocábulo eles exprimem, a um só tempo, razão e discurso, indissociavelmente. Ora, se o veículo do pensamento é o discurso, um não existe sem o outro. Por outro lado, é do cerne da cultura grega que o verdadeiro é inseparável do belo. Por isso, a verdade da razão e a beleza do discurso são interdependentes e autoinclusivos. Os especialistas concordam em que são estes os dois grandes axiomas da civilização helênica: indiscernibilidade dos binômios belo/verdadeiro e discurso/pensamento.

Segundo Platão e os estóicos, não pode existir um discurso belo que seja falso, nem tampouco um falso que seja belo. É por esse motivo que rejeitam a validade da Retórica. O paradoxo está em que, para repudiá-la, não têm outro meio senão utilizar a mesma técnica. No fundo, operam uma substituição meramente formal, mediante o emprego de idênticos processos. Negam-na, mas erigem em seu lugar uma retórica da beleza e da verdade desligada do real.

Foi essa mesma atitude que acerbamente levou o maior retórico do romantismo a proclamar guerra à Retórica e a sepultá-la no museu da literatura. É certo que o talento de Victor Hugo se transmuda em gênio ao trocar sua retórica de literato pela autenticidade de ardente panfletário e escritor de candentes romances de testemunho. Mas não deixa de haver a maior ironia no emprego dos processos argumentativos do discurso para pretender abolir a própria arte do mesmo.

Aristóteles, nos cerca de vinte anos em que freqüentou a Academia, jamais dissentiu dos ensinamentos do mestre. Após a morte deste, seguiu seu rumo independente e amiúde contrário, inclusive em pontos básicos, como na ontologia e na gnosiologia. Interessam-nos aqui o problema das relaçōes entre ética e retórica. Platão, coerente com sua dicotomia entre verdadeiro e falso, rejeita o verossímil, que pertence ao reino da opiniāo $(\delta o ́ \xi \alpha)$ e está eivado de relativismo, mentira, ilusão, produzidos pelas percepçōes dos sentidos. O discípulo, que só admite a existência de um único mundo constituído de entes e animado pelos princípios de 
matéria e forma, substância e acidentes; ato e potência, reconhece a imprecisão das fronteiras entre os pares antagônicos da verdade e do erro, beleza e fealdade, justiça e injustiça, bondade e maldade. Concebe um espaço neutro entre os elementos desses binômios, fazendo intervir os conceitos de persuasivo ou que tem capacidade de persuasāo ( $\pi \bullet \theta \alpha v o ́ v$ ) e de semelhante ou parecido (Elkós) ${ }^{1}$. Será

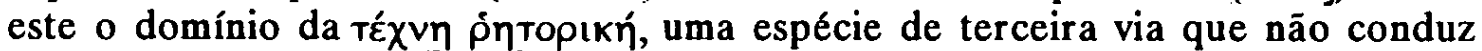
necessariamente a nenhuma das dos binômios, mas que tanto pode levar a uma como a outra, dependendo da conversão do $\pi(\theta \alpha v o ́ v . /$ cỉkós num ou noutro dos limites a que tendem. Intervém aqui a arte/técnica da persuasão. Neste campo se exercita a perícia do retor, dela dependendo a busca de razões mais ou menos convincentes, dissuasoras ou sedutoras, sugestivas ou desviacionistas. Ao artífice da persuasão - e à sua técnica - não interessam a verdade ou a falsidade da causa; interessa-lhe apenas mudar as coisas para fazer aceitar o seu discurso. Ele procura em seus arrazoados não a verdade ou a mentira, e sim a mente do destinatário. Utilizando a classificação de Arthur Schnitzler para os políticos, poderíamos dizer que há três espécies de retóricos que, para atingirem seus alvos, lançam mão de três tipos de manobra:

- os que turvam a água,

- os que pescam em água turva, e

- os que turvam a água para melhor pescarem.

É óbvio que os últimos são os mais engenhosos e eficientes.

Aqui reside uma primeira objeção ética à arte de argumentar para convencer. Por serem o persuasivo e o verossímil o seu fundamento, a manipulaçāo constitui a arma fatal. O relativismo e, por vezes, o niilismo são o seu campo de batalha.

Uma segunda objeção decorre da própria natureza do homem, na qual inextricavelmente se amalgamam o afetivo e o racional, residindo nessa fusão o verdadeiro poder da retórica. Quer isto dizer que o seu domínio é o das relaçōes humanas, onde o rigor e a exatidão dos conceitos abstratos se mesclam às emoções, paixões e vicissitudes do agir num mundo de afetos e rejeiçōes, de inclinaçōes e impulsos de toda a ordem.

Logo no início da Ética a Nicômaco (1094b), adverte Aristóteles de que "é próprio do homem culto e bem formado não exigir de cada ciência particular um grau de precisão incompatível com a natureza de seu conteúdo, pois, do contrário, poder-se-iam esperar do matemático argumentos simplesmente persuasivos e, do orador, demonstraçōes cabais".

\section{Homo Ethicus - Homo Rhetoricus}

Comunicar é da essência do homem. Do nível primário da consciência de si e do outro - à subliminar sofisticação da publicidade. No gesto mais instintivo, no som mais rudimentar que emita, no uso de mecanismos que operem seja informação seja mera sugestão, está presente o mesmo fenômeno de transferência de estados e intençōes, de sentimentos ou volições. O homem comunica-se desde o instante em que haure o sopro da vida, e continua a comunicar-se através do rastro que deixou. Ao articular o pensamento na fala, ele cria o 


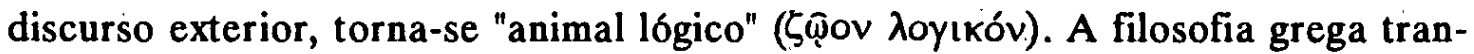
sitou da reflexão sobre o cosmos (Pré-socráticos) para a do homem concreto. Mas

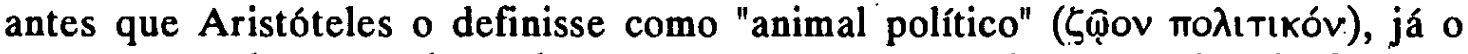
seu mestre colocara na boca de Sócrates que somente o homem é dotado de lógos

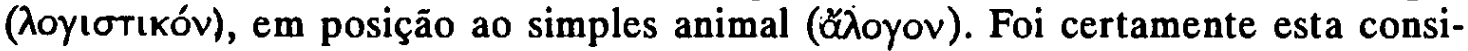
deração que induziu muitos pensadores modernos a preferirem a tradução de $\zeta$ ф̣ov

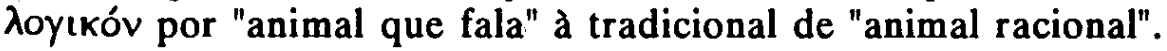

Antes que o homem "dissesse" o mundo em sua fala e assim tomasse consciência do ser (Die Sprache ist das Haus des Seins - Heidegger), podemos imaginar

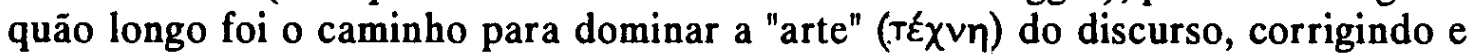
aperfeiçoando o dom da natureza (ingenium). Com a posse do discurso para "dizer" o mundo (a palavra é o lugar próprio da parusia do real - Pereira, 1976, p. XIX), o homem adquiriu seu maior patrimônio, que equivale à sua própria identidade de ser aí (Dasein). Para comunicar e comunicar-se, cedo descobriu que não bastaria "dizer", mas era preciso "dizer bem", tal como descobriu que não lhe era suficiente

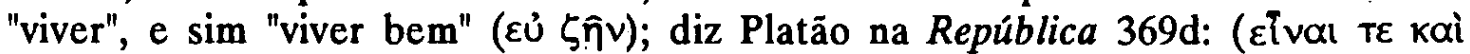
$\zeta \hat{\eta} v$ ). Nasce deste modo a bene dicendi scientia (Quintiliano, De inst: orat.II, 15, 34, fazendo eco à fórmula de Catão), que virá a ser objeto do primeiro tratado na época de esplendor da filosofia helênica. Cria-se a teoria do discurso (Aristóteles) para orientar seu exercício e alcançar seu alvo: a mente e a "paixão" (đá $\theta \circ$ s)

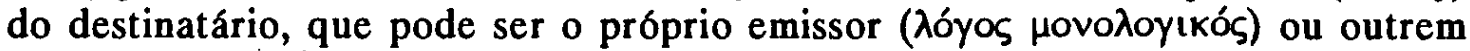

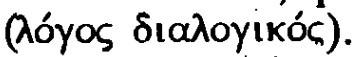

O domínio ético do discurso principia no ponto exato em que principia o da liberdade do receptor. Este pode ou não prestar-lhe atenção, numa escala que vai de máximo a mínimo, acolher ou repelir sugestōes, aderir ou opor-se a argumentos - ou muito simplesmente ficar na indiferença. Toda a comunicação retórica visa convencer, reforçar a crença ou lançar a dúvida (que não deixa de ser uma forma de convencer). Os especialistas das teorias argumentativas têm apontado alguns dilemas do processo retórico. Provêm eles do fato de os meios utilizados nesse processo serem, ao mesmo tempo, de natureza racional e afetiva (que já comentamos). Diz Pascal que todos sabemos da existência de duas entradas das opiniōes na alma - suas duas principais potências: 0 entendimento e a vontade (Pascal), 1964, p. 592) -, a primeira das quais é a mais natural, que adere às verdades demonstradas, constituindo a segunda uma via indigna, baixa e estranha, quase sempre levando o homem a consentir não pela prova, mas pelo agrado e prazer. Daí decorrem graves questōes, como estas:

- será legítimo ornar a elocução com os atavios da fala e gesto, ou, pelo contrário, o justo será contar apenas com a força dianoética da argumentação?

- o apelo aos sentidos que a comunicação física põe em jogo não toldará a razão, ou será que somente exerce o seu poder mediante uma combinação harmônica e integrada com eles?

- se o objetivo do discurso é a persuasão, como lidar com o problema do verdadeiro e do falso?

- quais as relaçōes, afinal de contas, entre ética e retórica?

- qual o verdadeiro estatuto da retórica ante as demais disciplinas" seu conteúdo será especializado, concentrado no "momento intelectivo dos significados", ou será antes "plurissignificativo e totalizante" (Barilli,.1985, 
p. 9), operando na vastidāo dos campos do saber, do agir e do comunicar?

Por outras palavras: atendo-nos à prática medieval do currículo escolar dividido por Marciano Capela e fixado por Boécio no triuium e no quadriuium, a retórica permanecerá enquadrada no primeiro como saber técnico formal, integrará o segundo como ciência de conteúdo, ou transitará livre entre os dois?

Outras questōes poderão ser ainda suscitadas, percebendo-se estreito nexo em seu encadeamento: a dilucidação de uma tornará claras as demais. Docere, mouere, delectare (ou, segundo Cícero, probare, flectere, delectare) são as três ordens de finalidades do discurso argumentativo. $\mathrm{Na}$ primeira, considera-se exclusivamente

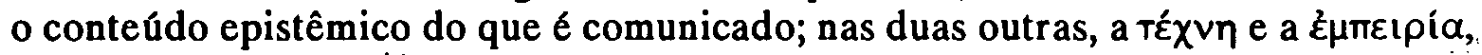
que agem sobre o ná $\theta$ os dos que recebem a comunicação. No processo retórico, a teleologia das três ordens não pode dissociá-las entre si, da mesma forma que no ato humano genuíno não é possível separar os elementos cognitivos dos volitivos ou emocionais, sob pena de retirar-lhes a autenticidade, que vai de par com a liberdade e a responsabilidade. Na expressão de Pascal (Barilli, ibid.), nele se fundem "vérité" e "volupté", equação de entendimento e vontade.

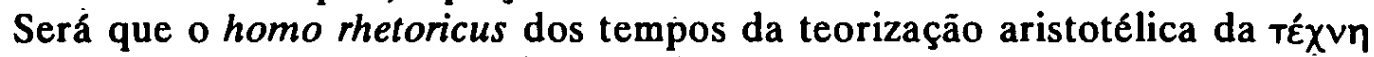
p̊ntopı́ń não é o mesmo de hoje, diferindo apenas no modus de idênticas dimensōes do intelecto e da sensibilidade? Lembra Umberto Eco (1984, p. 300) que o problema da nossa época consiste em integrar essas novas dimensōes naquelas sobre as quais todos os nossos modos de comunicação ainda se sustentam.

Desde os alvores da filosofia, a retórica apresenta uma relação ambígua com a ética: positiva, no velho ideal do orator como uir bonus dicendi peritus, segundo o define Catão; negativa, quando, enquanto arte de lidar com a psique dos ouvintes ( $\psi \cup \chi \alpha \gamma \omega \gamma i \alpha)$, se põe a serviço de objetivos moralmente neutros e até mesmo antiéticos (caso dos demagogos).

\section{Homo Ethicus}

O homo rhetoricus pressupõe o homo politicus. O mundo retórico é o das relações humanas, e estas só acontecem se a vida do homem estiver associada à de outros homens. As duas categorias - rhetoricus e politicus - integram a mais ampla e natural - socialis. Em sociedade, o homem instintivamente utiliza seus conceitos e impressões quando ajuíza ou de algum modo aprecia os seus semelhantes, ou quando se considera vítima de injustiça e se julga merecedor de maior consideração. Quer dizer, o homem pondera e emite juízos de valor. Esta a sua dimensão ética. Conhece o que é bom e o que é mau. Mas com que medidas e critérios afere sua escala de valores? Haverá leis ou regras que dêem alicerce a essa escala? A ordenação da sociedade dos homens assenta, pois, numa etopéia.

A historiografia da ética nos revela múltiplos acessos a uma definição. Uns identificam-na com a ciência do bem e do mal, institutiva de códigos e normas de comportamentos válidas para determinado grupo ou para todos em geral. Outros fazem dela uma ciência moral empírica, alicerçada em "fatos" da vida social e individual, na fenomenologia da consciência ou na análise da linguagem e da lógica 
das expressões éticas. Outros ainda preferem uma ética material de valores baseada numa ontologia axiológica.

Importa caracterizar a ética enquanto doutrina que norteia o indivíduo na escolha do caminho a seguir diante de questões nodais para a sua situação vital, como, por ex.: Que bem devo eleger dentre os que tenho na frente? Que valores devo aceitar? Há um valor supremo, ou sumo bem, em cuja hierarquia ascendente se ordenem outros valores? Que tipo de vida quero levar? Como agir? Que pretendo em minha condição de homem?

A complexidade das questōes aponta vários modelos de ética, sumariamente estruturados segundo três eixos:

- material: diz respeito a uma ética de bens da vida prática, do tipo epicurista; considera a vida sob o ângulo da fruição e suas conseqüências, que devem ser bem calculadas;

- ontológico: sinaliza uma ética do ser, conduzindo para um ideal de perfeição e pleno desenvolvimento, podendo atingir a iluminação e a consumação eudemônica;

- deontológico: segue imperativos do dever imposta de dentro (consciência moral) ou de fora (preceitos).

No jogo envolvente, por vezes vicariante e supletivo, dos três eixos, podemos recortar o corpus de uma doutrina substancial ao homo ethicus.

$\mathrm{Na}$ ambivalência e interação dos dois tipos de "homines" reside a "uis dramatica" da condição humana. Em seu horizonte frontal, o bem resplendente da Verdade; no horizonte dorsal, o império sombrio do Erro. Contudo, a vida prática do homem transcorre entre esses pólos opostos, em terreno impérvio ao maniqueísmo, mas povoado de enganos e ilusões.

Façamos breves considerações de caso sobre o tema das relaçōes da ética e da retórica, em sua zona de fronteira. $O$ orador pode ser vítima de um processo de auto-ilusão produzido pela ética, caso em que a retórica se torna sua ancilla fallaciae. Nietzsche e a psicanálise incorreram freqüentemente nesta cilada ao tentarem racionalizar fenômenos do domínio ético. Outro caso é o de admitir princípios absolutos, incondicionais, como o critério de validade ética a priori (vontade de Deus, imperativo categórico, etc.), esquecendo que tal critério se aplica a condições empíricas, a posteriori. $O$ auto-engano do retor é provocado pelo fato de muitas vezes o relativo se oferecer sob a máscara do absoluto, e em sua consciência surgirem imperativos hipotéticos como sendo imperativos categóricos. No processo de auto-engano pode dar-se interação da ética e da retórica, como quando um indivíduo está convicto de que seus atos correspondem ao dever moral universalmente válido. $\mathrm{Na}$ condição de especialista, homem de estado, servidor público, cumpre determinada funçāo que reputa útil à comunidade (fim explícito, retórico), sem de fato servir necessariamente a si mesmo, ao povo, à instituição (fim não declarado, real). A retórica do primeiro fim produz uma legitimação ética do segundo, de acordo com os valores predominantes na sociedade. $O$ autor do discurso acredita nisso, de forma que o auto-engano pode conferir à imoralidade as aparências de moralidade. Trata-se de ilusão, mas não necessariamente de perfídia ou cinismo (Herra, 1988, p. 27).

Será que as técnicas retóricas são moralmente neutras? Para defender sua neutralidade, há que defender também que é moralmente irrelevante um homem 
chegar a determinada opinião ou crença por uma via racional ou por qualquer outra não racional. Para sustentar que isso é moralmente irrelevante, é forçoso sustentar igualmente que o exercício pelo homem de sua racionalidade é irrelevante para ele se apresentar como agente moral, ou seja, para decidir se faz jus a ser chamado de "responsável" e suas açōes de "voluntárias". Deste modo, pressupõem-se diferentes elucidaçōes dos conceitos de responsabilidade e de açōes voluntárias pelas diferentes atitudes morais para o estabelecimento das técnicas da persuasão. A tarefa filosófica de elucidação não pode, por isso, ser moralmente irrelevante. $E$ assim que Sócrates, opondo-se aos sofistas, demonstra que a retórica não é uma arte genuína, mas uma espúria imitação de arte (Mac Intyre, 1966, p. 27 e 28).

\section{Nota}

1- Para o conceito de $\pi$ lӨavóv, vd. Platão, Górgias 458e; 479c; Fédon 88d; Aristóteles, Ret: 2,22,3, etc; para Elıós, vd. Aristóteles. Anal. pr. 2,27; Ret. 1,2,15.

\section{Referências Bibliográficas}

ARISTÓTELES. Opera. Berlim: Academia Borussica, apud W. de Gruyter et socios, 1961,5 vols.

BARILLI, Renato. Retórica. Lisboa: Editorial Presença, 1985.

ECO, Umberto. Viagem na Irrealidade Cotidiana. Rio de Janeiro: Nova Fronteira, 8 ed. 1984. Cap. "O Cogito interruptus", de Della Periferia dell'Impero, 1967.

HEIDEGGER, Martin. Sein und Zeit. Tubingen: M. Niemeyer, 1972.

HERRA, Rafael Angel. "Kritik der Globalphilosophie". In: WIMMER, Franz. Vier Fragen zur Philosophie in Afrika. Asien und Lateinamerika. Viena: PassagenVerlag, 1988.

MAC INTYRE, Alasdair. A short history of Ethics. Nova York: MacMillan Publishing Company, Collier Books, 1966.

NIETZSCHE, F. W. L'origine de la tragédie ou Hellénisme et pessimisme. 6 ed. Paris: Mercure de France, 1911.

NIETZSCHE, F. W. La naissance de la Philosophie à l'époque de la tragédie grecque. $6^{\mathrm{e}}$ éd. Paris: Gallimard, 1938.

PANOFSKY, Erwin. Gothic Architecture and Scholasticism. Princeton: 1951.

PASCAL. De l'art de persuader, In: Opuscules, section II. Oeuvres Complètes. Paris: Pléiade, 1964.

PEREIRA, Miguel Baptista. Introdução à trad. port. de F. E. PETERS, Termos Filosóficos Gregos. Lisboa: Gulbenkian, 1976.

PLATÃo. Opera. Oxonii: e Typographeo Clarendoniano, ts. 1-v, 1973-5.

QUINTILIANO. De Institutione Oratoria. Paris: Panckoucke, 1829.

SCHOPENHAUER, Arthur. Die Welt als Wille und Vorstellung. Atlas Verlag Köln, 2 ed. 1844. 
MENDES, J.P. The ethic of argumentation. Ancient Rhetoric/Modern Rhetoric. Classica, São Paulo, 5/6: 207-214, 1992/1993.

ABSTRACT: The art of controversy - dialectic - dealing with truth and its perception of falsehood: the art of argumentation - rhetoric - working in the realm of plausability, of the seemingly realistic in order to change options and influence preferences. Human nature is molded by emotions and rationality; philosophy/dialectic belonging to the latter and rhetoric to the former. While dialectic acts on the mind of the questioner, rhetoric acts on the will, the emotions and the passions to gain adhesion. Considering that practical experience does not always combine with the light of reason, generating persuasion; and considering the non-existence of a logic of value-judgements, the conduct of man falls into the domain of ethics raising a number of questions: from manipulation to seduction, from caprice to passionate influence, from blindness and selfdelusion to the usurpation of individual liberty. In other words, philosophy seeks out impersonal truths; rhetoric attempts to make one person's opinion prevail over another's. And it is here that ethical questions arise.

KEY WORDS: Ethics, rhetoric, theory of argumentation, philosophy. 